\title{
Coherencia, integridad y vida cotidiana
}

\section{Coherence, integrity and daily life}

\section{Luz Mary Sánchez-Rengifo}

Trabajadora social. Magister en Orientación y Terapia Familiar y de Pareja

Universidad del Valle. Cali, Colombia

https://orcid.org/0000-0002-3102-5994•lumsanchez@gmail.com
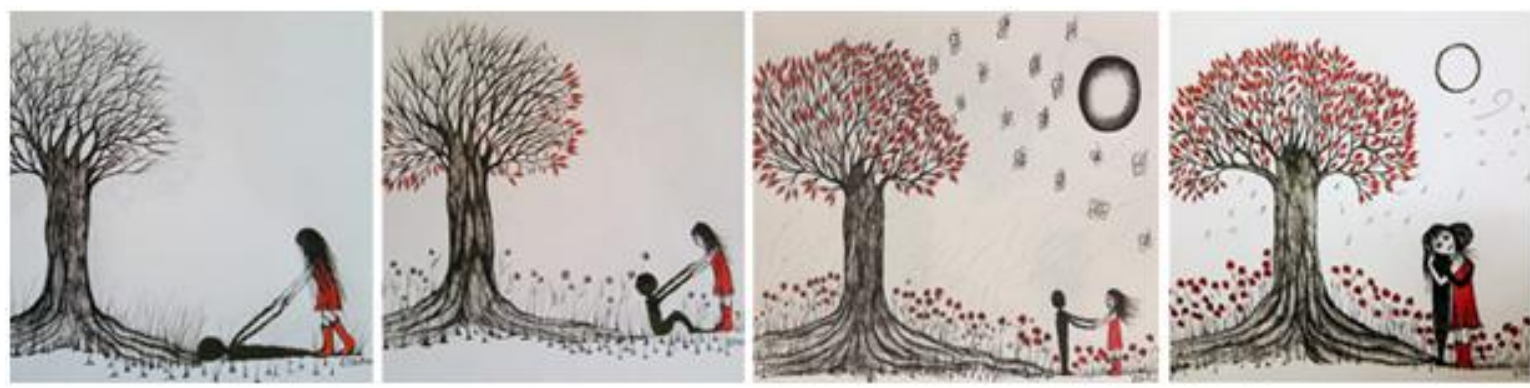

La niña se integra. Obra de Edna Rocío Pérez-Gómez.

\section{Introducción}

En la actualidad, el concepto de coherencia es de frecuente mención y se relaciona directamente con conceptos como congruencia, integridad, integración. En general, podemos decir que la coherencia, se refiere a la relación, a la conexión o a la unión entre diferentes cosas, o a aquello que interconecta y mantiene unidas las partes de un todo. Es decir, la coherencia alude a la relación lógica o consecuente entre las diferentes partes de una afirmación, de un discurso, de una postura y de un comportamiento.

Puede utilizarse como un juicio para referirse tanto a la redacción de un texto, a la argumentación de un discurso verbal y escrito, como a un comportamiento, así como a las relaciones entre los seres humanos, etc.

Estas notas llevan al lector por espacios teóricos y prácticos que le faciliten comprender, en general, el concepto de coherencia especialmente en el contexto de las relaciones interpersonales. La coherencia es útil para la reflexión sobre las relaciones

(7)(-) Esta obra está bajo una Licencia Creative Commons Atribución-NoComercial-CompartirIgual 4.0 Internacional.

¿Cómo citar este artículo? / How to quote this article?

Sánchez-Rengifo, L.M. (2020). Coherencia, integridad y vida cotidiana. Prospectiva. Revista de Trabajo Social e intervención social, (30), 01-22. doi: 10.25100/prts.v0i29.7195. 
Sánchez-Rengifo

interpersonales, la salud mental y la vida cotidiana, pues aplica tanto en la observación a otros como en el trabajo auto reflexivo. Se ilustra con algunos ejemplos provenientes de la vida cotidiana, la literatura y el cine.

\section{Coherencia en un texto escrito o en un discurso verbal}

Un texto escrito o un discurso oral es coherente cuando está estructurado de manera apropiada y no se contradice a sí mismo ni en las ideas, ni en la forma en que éstas se expresan. Encontramos lo que se llama un hilo conductor: una idea central y alrededor de ella ideas complementarias que refuerzan su contenido. Un texto coherente, aunque sea complejo, se caracteriza por la claridad, precisión y concatenación de ideas. Un texto incoherente, por lo general, no tiene continuidad, contiene contradicciones, ambigüedades, su objetivo y tema principal no son claros por lo que resulta ininteligible o por lo menos confuso.

Presento este aparte con el fin de que el lector haga conexiones con el concepto de coherencia aplicado a otros ámbitos, aunque no me detendré a profundizar en ello.

\section{Coherencia de una Persona}

Se dice que un sujeto es coherente cuando su actitud es consecuente con su postura mental. Se observa correspondencia entre su forma de pensar, sentir y de actuar.

El ser humano se caracteriza porque es dinámico: mientras haya vida hay oscilaciones, movimientos, su ausencia está ligada a la muerte. La cultura popular plantea que los extremos son dañinos. Cuando se trata de la relación humana, lo saludable es un movimiento oscilatorio, el punto en que nos ubiquemos en cada momento tiene que ver con los sujetos con los que nos relacionamos, el contexto, la situación y la oportunidad. Lo cuestionable son las posiciones fijas, ubicadas en los extremos o en el medio ${ }^{1}$.

Para que un ser humano sea coherente se requiere que tenga un alto nivel de integración. Un sujeto integrado se caracteriza porque su parte luminosa y su parte oscura son incluidas y aceptadas; aprende de ellas lo que sea necesario aprender y aparecen mezcladas en su comportamiento cotidiano. La mixtura enriquece y puede aportar sabiduría y comprensión tanto a sí mismo como a los demás. Cuando una persona no está integrada se enorgullece de su parte luminosa y no acepta como propia su parte oscura y, si la visualiza, la niega y se avergüenza de ella. En este último caso pueden darse dos posibilidades que aparentemente son contradictorias, pero en el fondo responden al

1 Para mayor profundidad en lo que concierne a este párrafo, véase a Huneeus (1991); Morin (2001) y Ugazio (2001). 
mismo patrón. Se reconoce y ataca en otros lo que no se ha podido reconocer e integrar en sí mismo o se asume un comportamiento liberal con los demás, y en la vida íntima se asume un comportamiento excesivamente conservador. Por ejemplo, el homosexual que no se siente bien siéndolo y ataca a los homosexuales. O el que predica la liberación sexual o el uso de marihuana en la vida pública, pero en su vida familiar o de pareja no lo permite y lo juzga negativamente.

Si queremos lograr la integración debemos aceptar nuestros defectos e integrarlos con las que consideramos nuestras cualidades y así, obtendríamos un resultado favorable en el que se entretejen características positivas y negativas. Hay que tener en cuenta que lo negativo en un contexto, en otro puede ser positivo, o a la inversa.

Si integramos nuestras características negativas con las positivas, la expresión de las primeras no será dañina ni para nosotros ni para aquellas personas con las que nos relacionamos, porque la mezcla las suaviza. Así estaríamos aceptando que cometemos errores, que somos imperfectos; mientras que, al negarlas, nos esclavizan y se expresan sólo en nuestras conductas, en nuestro comportamiento no verbal ${ }^{2}$ o de manera oculta y con todo el vigor y fuerza. De ahí el planteamiento de que no hay personas totalmente malas o totalmente buenas, e incluso se llegue a decir que de las personas excesivamente buenas debemos desconfiar, porque la parte negativa está agazapada y de seguro sale en la oscuridad y con los más débiles. También podemos decir que escuchar y reconocer nuestro lado oscuro en ocasiones puede otorgarnos más sabiduría que nuestro lado luminoso.

Los seres humanos somos falibles, imperfectos y si bien debemos luchar por lograr la coherencia, la integración, minimizar los errores, equivocarnos menos, tenemos que aceptar que nunca alcanzaremos una coherencia total. Debemos contentarnos con un nivel de coherencia relativamente alto, lo suficiente como para permitirnos vivir una vida individual y relacional satisfactoria, y estar atentos a nuestro comportamiento y evaluarnos constantemente.

En este sentido, Erickson (1981) decía que la integridad, entendida como un comportamiento coherente, honesto y recto, es muy difícil de alcanzar y que si acaso el ser humano la logra, es al final de su vida. Él definió ocho etapas del desarrollo humano, de las cuales la octava y última corresponde a la vejez, precisamente la fase en la que la tarea primordial del ser humano es lograr la integridad con un mínimo de desesperanza. Si a pesar de las limitaciones de su cuerpo, de sus enfermedades, de la muerte de sus seres queridos y de la inminencia de su propia muerte, la evaluación de su vida tiene un buen

2 Aunque las actuemos, no nos damos cuenta o negamos que lo estamos haciendo. Son pulsiones que actúan desde el inconsciente. 
Sánchez-Rengifo

balance y muestra integridad en su comportamiento, en sus relaciones consigo mismo y con los demás, diremos que ha logrado un alto grado de coherencia entre lo que piensa, siente y hace.

Para mayor ilustración de lo planteado, recomiendo al lector el video de Debbie Ford (2009) "El Efecto Sombra", así como los artículos de Chimananda Ngozi Adichie (2018) "El silencio es un lujo que no podemos permitirnos" publicado en el periódico EL PAÍS de España, y el de Moisés Wasserman (2016) "El temor a la gente demasiado buena" publicado en el periódico El TIEMPO. Continuemos profundizando en la coherencia de los seres humanos, teniendo como marco la teoría de la comunicación humana.

\subsection{La Comunicación}

$\mathrm{Al}$ encontrar en un interlocutor una contradicción o inconsistencia entre lo que cree y hace, es decir, entre aquello que 'predica' y su 'comportamiento', podemos decir que hay incoherencia o falta de integridad en esa persona. La comunicación humana es un proceso complejo, como veremos a continuación al examinar sus rasgos más importantes:

\subsubsection{La Descalificación}

En la teoría de la comunicación humana, se han estudiado interacciones comunicacionales que ilustran diferentes formas de incoherencia y coherencia; encontramos formas inteligentes de salir airoso, manteniendo la coherencia, en un contexto adverso, hasta formas que hacen daño a los participantes en la interacción comunicativa.

A estas interacciones se las denomina formas de descalificación de la comunicación y consisten en comunicarse, de un modo que invalide la propia forma de comunicarse o la del interlocutor. Watzlawick, Helmick y Jackson (1983), lo plantean así:

Las descalificaciones abarcan una amplia gama de fenómenos comunicacionales, tales como auto contradicciones, incongruencias, cambios de tema, tangencializaciones, oraciones incompletas, malentendidos, estilo oscuro o manierismos idiomáticos, interpretaciones literales de la metáfora e interpretación metafórica de las expresiones literales, etc. (p. 76).

Veamos las dos formas de decir sin decir. Hay formas de comunicarse que pueden constituir una buena manera de complacer al interlocutor mediante el sutil arte de:

- No decir nada, diciendo algo, o lo que podríamos denominar el lenguaje "cantinflesco". Suelen recurrir a este tipo de comunicación las personas que se ven atrapadas en una situación en la que sienten la obligación de comunicarse y 
al mismo tiempo, desean evitar el compromiso inherente a toda comunicación, comprometerse o cumplir con lo dicho. Recomiendo ver el video "Súper Cantinflas y la relatividad" de Alberto Tosky (2013).

- Decir algo de manera paradójica, irónica o metafórica, cuando el contexto no permite expresarlo clara y explícitamente.

Por ejemplo, se dice que cuando los nazis invadieron Austria, Freud fue declarado enemigo del régimen, tanto por su origen judío como por ser psicoanalista. Muchas de sus obras fueron quemadas e incluso dos de sus hijos fueron apresados por la Gestapo para ser interrogados.

A los 80 años de edad y enfermo de cáncer, Freud tuvo que exiliarse en Londres para salvar su vida. La princesa Marie Bonaparte, con ayuda de otras figuras influyentes de la época, logró reunir una pequeña fortuna con la que se le concedió la visa de salida al psicoanalista y a su familia directa.

La Gestapo puso una condición para permitir el exilio de Freud y era que firmara un documento en el que decía que el régimen lo había tratado "con todo el respeto y consideración debido a mi reputación científica y podía vivir y trabajar en plena libertad". Freud antes de partir, efectivamente firmó el documento y agregó la irónica frase, "Recomiendo encarecidamente la Gestapo a todos" (History Channel, 2013).

También, se encuentran unos diálogos que se le atribuyen a Gandhi con un profesor suyo. Independientemente de su veracidad, ilustran el ingenio para comunicar lo incomunicable, en un contexto amenazante.

Cuando Mahatma Gandhi estudiaba Derecho en Londres, un profesor de apellido Peters le tenía mala voluntad... pero el alumno Gandhi nunca le bajó la cabeza y eran muy comunes sus encuentros. Un día Peters estaba almorzando en el comedor de la Universidad y él venía con su bandeja y se sentó a su lado...

El profesor muy altanero, le dice: “¡Estudiante Gandhi, Ud. no entiende! Un puerco y un pájaro, no se sientan a comer juntos". A lo que Gandhi le contestó: "Esté usted tranquilo profesor, yo me voy volando", y se cambió de mesa... El profesor Peters se puso verde de rabia, porque entendió que el estudiante le había llamado Puerco y decidió vengarse con el próximo examen...

Pero el alumno Gandhi respondió con brillantez a todas las preguntas del examen... Entonces el profesor le hace la siguiente interpelación: “Gandhi, si Ud. va caminando por la calle y se encuentra con dos bolsas y dentro de ellas están la sabiduría y mucho dinero, ¿cuál de los dos se lleva?”. Gandhi responde sin titubear: “¡Claro que el dinero, profesor!". El profesor sonriendo le dice: "Yo, en su lugar, hubiera agarrado la sabiduría, ¿no le parece?" Gandhi responde: "Cada uno toma lo que no tiene profesor". El profesor Peters, histérico ya, escribe en la hoja del examen: "IDIOTA" y se la 
devuelve al joven Gandhi. Éste toma la hoja y se sienta... Al cabo de unos minutos se dirige al profesor y le dice: "Profesor Peters, usted me ha firmado la hoja, pero no me puso la nota..." (Central de Radios, 2017).

Esa misma capacidad la tenía Jaime Garzón, quien a través de sus personajes lograba decir 'verdades' y mantener al mismo tiempo un clima y una relación amable con el interlocutor. La habilidad de Jaime Garzón, estaba en la combinación que hacía entre lo verbal y lo no verbal, por eso no doy un ejemplo textual, sino que invito a ver sus videos. Un ejemplo claro está en Jaime Garzón "Heriberto de la Calle" entrevista a Horacio Serpa (13 de agosto del 2016).

\subsubsection{La Interdependencia con otros seres humanos}

Corrientemente escuchamos que no hay que vivir del qué dirán, que no hay que darle importancia a lo que otros piensen de nosotros. Planteo que, así como no sería saludable que no nos importe para nada la opinión ajena sobre nosotros, tampoco sería sano vivir pendiente en extremo de la misma. Lo sano, nuevamente, es la oscilación entre los dos extremos pues si la percepción de los otros acerca de nosotros no nos importara en lo más mínimo, estaríamos psicóticos.

Al respecto, Laing, Phillipson y Rusell-Lee (2001), plantean que “El mundo está poblado por otros y estos otros no son simples objetos en el mundo: son centros de reorientación hacia el universo objetivo... La presencia de estos otros tiene un profundo efecto reactivo sobre mí" (p. 13). Y más adelante estos autores mencionan:

... la autoidentidad ( $<<$ yo observando $>>$ a $<<$ mí $>>$ ) está constituida no sólo por nuestra observación de los otros observándonos y nuestra reconstitución y alteración de estas visiones de los otros acerca de nosotros. En este nivel más complejo, más concreto, la autoidentidad es una síntesis de mi observación de mí y de mi visión de la visión que los otros tienen de mí. Estas visiones que los otros tienen de mí no necesitan ser aceptadas pasivamente, pero no puedo ignorarlas al desarrollar mi sentido acerca de quién soy. Pues, aunque rechace la visión de otro sobre mí, la incorporo, rechazada, como parte de mi identidad. (pp. 15-16).

La percepción de los otros acerca de nosotros y del vínculo que tenemos con ellos, es más importante para nosotros en cuanto más cercano e íntimo es el vínculo. Por ejemplo, en las relaciones madre-hijo o en las relaciones de pareja. Laing, Phillipson y Rusell-Lee (2001) plantean que en las relaciones interpersonales estrechas, la visión que el otro tiene de mí, es tan importante, como la visión que yo tengo de mí mismo aunque, en el mejor de los casos, ambas visiones no son idénticas, sólo son más o menos similares. Así que, ésta más o menos determina, más que cualquier otro factor, la naturaleza de nuestra relación y, por consiguiente, mi sensación y la del otro de ser entendidos y tener una 
identidad que está validada por el otro. De esta manera, me siento reconocido por el otro, tanto en mi yo, en tanto persona independiente, como en el vínculo que nos une. En conclusión, la claridad es acerca del sí mismo de cada uno como sujeto, el yo y acerca del vínculo que los une, el nosotros: qué es cada uno para el otro3 ${ }^{3}$

Tenemos entonces que, si la naturaleza de la relación no es clara o no es la que cada sujeto desea o hay una lucha alrededor de su definición, claramente es una relación que no puede ser satisfactoria para los integrantes. Una relación satisfactoria por lo general se autodefine tácitamente si existe coherencia entre la forma de relacionarse y la forma en que se nombra la relación. Al respecto, Watzlawick et al. (1983) afirman que:

Para evitar malentendidos con respecto a lo dicho, queremos aclarar que las relaciones rara vez se definen deliberadamente o con plena conciencia. De hecho, parecería que cuanto más espontánea y 'sana' es una relación, más se pierde en el trasfondo el aspecto de la comunicación vinculado con la relación. Es decir, hay coherencia entre la forma en que se relacionan y la forma en que nombran la relación. Del mismo modo, las relaciones 'enfermas' se caracterizan por una constante lucha acerca de la naturaleza de la relación, mientras que el aspecto de la comunicación vinculado con el contenido se hace cada vez menos importante. (Watzlawick et al., 1983, p. 54)4.

En consecuencia, lo saludable en una relación permanente entre dos personas es que la naturaleza de la relación sea clara: 'somos amigos', 'novios', 'amantes', 'esposos', etc. Hay

3 La tensión se produce cuando uno de los miembros de la diada (pareja, madre e hijo, hermanos, amigos, etc.) se atribuye a sí mismo características y capacidades que son ignoradas o invalidadas por el otro miembro. Por ejemplo, cuando un individuo ignora los éxitos del otro o se niega a reconocer que el otro es capaz de prestar apoyo, de ayudar, de enseñar o proporcionar algún tipo de gratificación, el otro miembro puede experimentar un intenso malestar porque puede sentirse descalificado, rechazado o tener la sensación de que sin importar lo que haga, no llegará a complacer al otro. Ese apoyo, ayuda o regalo, puede parecer amoroso a quien lo ofrece, pero presuntuosamente paternalista o dominante, a quien lo recibe, etc. Es probable que estas diferencias en la interpretación se basen en la experiencia o en el aprendizaje previo.

4 En la teoría de la comunicación humana se plantea que la comunicación tiene dos niveles: el contenido y la relación. El contenido se refiere al qué de la comunicación, son los datos, las palabras, las ideas, los discursos, lo que se puede decir con el lenguaje y tiene las ventajas y las limitaciones propias de éste. Si bien la forma preferencial en la que se expresa el contenido es la verbal, vale decir que también es posible expresar contenidos de manera no verbal, por ejemplo, el asentir o negar con la cabeza, el lenguaje de las señas, en el que se encuentran códigos muy elaborados como los utilizados por los sordomudos. La relación se refiere al cómo de la comunicación, tiene que ver con la calidad de la relación entre los comunicantes y con los sentimientos, emociones, actitudes, fantasías, confianza, sospecha, etc., presentes en ella. La calidad de la relación es uno de los factores influyentes en la interpretación del contenido; si hay una buena relación, será más fácil afrontar las diferencias o el conflicto en el contenido; mientras que cuando hay problemas en la relación, las personas por lo general tratan de resolverlo en el contenido, lo cual lleva a confusión, pues lo adecuado sería dejar el contenido a un lado y ocuparse de lo que está ocurriendo en la interacción (Para ampliar estos conceptos véase Watzlawick et al., 1983, p. 52). 
ocasiones en que, a pesar de vivir juntos, no se puede verbalizar o ponerle nombre a la relación, porque uno de los miembros lo prohíbe implícita o explícitamente. Esto hace mucho daño porque, aunque viven como marido y mujer, se comportan socialmente como sí no lo fueran. A continuación, ilustro este último concepto, que es de vital importancia para comprender la coherencia.

\subsubsection{Comportarse como si no estuviera pasando nada}

El comportamiento como si, puede oscilar entre lo sano y lo insano y se puede dar en diferentes situaciones ${ }^{5}$. Es un comportamiento que se desarrolla de manera normal en el ciclo vital de los individuos, es necesario para el buen desempeño social, aunque puede devenir en comportamientos dañinos. Cuando el comportamiento como si es dañino, se caracteriza por la negación, el ocultamiento, la distorsión, la representación, el engaño. En algunas ocasiones el sujeto finge y en otras, el comportamiento es totalmente inconsciente.

En consecuencia, encontramos en la interacción humana múltiples ejemplos del comportamiento como si, que pueden inducir o prefigurar tanto comportamientos positivos como negativos para la salud de los participantes. Por ejemplo, si a una persona sana mentalmente se la trata como si estuviera loca y se la interna en un hospital psiquiátrico, como se observa en las películas "Atrapado sin salida" dirigida por Milos Forman (1975) y "El sustituto" dirigida por Clint Eastwood (2008), lo más probable es que termine presentando los síntomas de un paciente psiquiátrico, o al contrario si a un paciente psiquiátrico, además de otros elementos de tratamiento, se le trata como a una persona sana mentalmente, puede ser el comienzo de su recuperación como se observa en la película "Nise: el corazón de la locura”, de Berliner (2016).

El comportarnos como si lo que queremos que suceda ya está sucediendo, ha sido incorporado a los procesos terapéuticos de terapia breve por Watzlawick y Nardone (2000) y también ha sido incluido en ejercicios con fines terapéuticos por Anderson (1999). Esto

5 Enuncio algunas de las situaciones en las que se puede observar este comportamiento: en la vida cotidiana se utiliza como juego. Una persona se comporta como si, y solamente lo sabe ella, de esta manera logra engañar a otros. En la película "El embajador de la India” (Ribero, 1986), vemos un ejemplo claro. Niegan una situación difícil, en lugar de afrontarla. Una o varias personas se comportan como si nada hubiera pasado, como si el negar o no mencionar la existencia del hecho, lo hiciera desaparecer. Se fingen sentimientos, satisfacciones, etc. Para mantener una determinada fachada social, pasado un tiempo donde el fingimiento ha imperado, los participantes llegan a confundirse y a creerse ellos mismos las mentiras. Hay momentos en que se distorsiona, aunque sea transitoriamente, el modo en que la persona se concibe a sí misma y a la realidad en la que está inmersa. También puede ocurrir que un niño o un adulto traten de exaltar la imagen de su agresor, como una forma de preservar la imagen de sí mismo y/o mantener la fachada social: El miembro de una pareja trata de ocultar el maltrato del que es objeto por parte de su esposo o esposa y evitar así la censura familiar y social. El niño que, como afirma Cyrulnik, (2001, p. 172) inventa unos padres perfectos disociados de la realidad que padece, con el fin de salvar su propia imagen. A quien quiera profundizar en el comportamiento como si, le recomiendo revisar el capítulo 5 del libro Mitos y secretos familiares (Sánchez y Escobar, 2009, p. 214). 
ha llevado a que el comportamiento como si, se convierta en una técnica terapéutica que incita a la acción, a comportarse como si el cambio ya se hubiera dado o se está dando, tal como lo plantea la nota que circula en WhatsApp acerca del filósofo y psicólogo estadounidense William James, quien junto con Charles Sander Peirce, fundó la Escuela filosófica del pragmatismo, y a quien se le atribuye la frase "¡Sí quieres tener una cualidad, actúa como si ya la tuvieras!". El mensaje que circula por WhatsApp dice: “Una vez le preguntaron cuál consideraba que era el descubrimiento más importante en el campo del desarrollo humano en los últimos cien años. Su respuesta fue la siguiente: 'Hasta ahora se pensaba que para actuar había que sentir. Hoy se sabe que el sentimiento aparece cuando empezamos a actuar. Este es para mí el descubrimiento más grande del siglo en el campo del desarrollo humano. James resume el descubrimiento con el siguiente adagio: 'El pájaro no canta porque sea feliz, es feliz porque canta'. Aunque usted se deprima, si empieza a actuar como si fuera feliz, acabará sintiéndose feliz, y por lo tanto lo será. 'El comportamiento cambia la emoción, y la emoción cambia el pensamiento'. La mayoría de la gente dice: 'lo haré el día en que me sienta bien'. No es este el camino. Comience a actuar inmediatamente, y las cosas cambiarán dentro y fuera de usted. Intención sin acción, es ilusión. Atrévase a hacer y el poder le será dado".

En la cultura Trobriand, según Bateson (1976) “...esos nativos manifiestan continuamente un hábito de pensar basado en la suposición de que el actuar como si una cosa fuera de determinada manera, hace que ésta sea así" (p. 201). Esta forma de pensamiento es la que está implícita en lo que Watzlawick et al. (1983), denominaron profecía autocumplidora6, solo que en este caso la premisa en lugar de ser positiva, es negativa.

En la película “El Piano” de Campion (1993), se explicita en varias situaciones el comportamiento como si. La película transcurre en Nueva Zelanda, los personajes son ingleses y aborígenes Maories. Los ingleses están preparando una representación teatral de una situación violenta y presentan los ensayos, donde una de las mujeres de la servidumbre es llamada para que actúe y se asusta cuando el sacerdote quiere representar con sombras como si le estuviera dando un hachazo, luego ya se acostumbra y puede disfrutar en el ensayo la pantomima y hace como si se asustara y luego ríe. Posteriormente ya en la representación, uno de los maoríes presente en el público intenta participar, salvando a las mujeres agredidas, pues toma la situación como si fuera real. Es decir, evidencia que en esa cultura, no hace parte del proceso de socialización, el aprendizaje del comportamiento como si. Este aprendizaje es el que nos permite, entre otras cosas,

6 Estos autores denominan profecía autocumplidora a la situación en que una persona parte de una premisa negativa y se comporta como si fuera cierta. La conducta asumida provoca en los demás la reacción (temida) frente a la cual esa conducta sería una reacción consecuente. Es decir, las conductas de la persona o personas provocan la reacción negativa que han predicho ocurrirá. Un ejemplo claro son las maldiciones. 
representar o asistir a representaciones, que aunque nos puedan llegar a afectar emocionalmente, sabemos que no están ocurriendo en realidad, sino que son seres humanos actuando.

Hay otra situación que se refiere exclusivamente a los personajes ingleses: La actriz principal ha perdido su piano, el cual es supremamente significativo para ella, y decide actuar como si estuviera tocando el piano en la mesa de la cocina y en este comportamiento participa su hija acompañándola, cantando. Su esposo, quien se ha mostrado insensible a sus necesidades emocionales y en especial no ha podido comprender el significado que tiene para ella tocar el piano, irrumpe sorpresivamente en esta escena; mostrando preocupación, le pregunta a la empleada más experimentada “¿Qué pensarías, si alguien tocara una mesa de cocina, como si fuese un piano?" y concluye que su esposa puede tener una afección cerebral, por no decir que cree que está enloqueciendo.

Tenemos entonces en nuestras manos, con el comportamiento como si, una herramienta potente de comportamiento; de nosotros depende con qué orientación la utilizaremos, negativa o positiva. En este sentido, Bateson (1976) hace referencia a la necesidad que tienen los seres humanos de actuar bajo el supuesto de esperar por sus actos algún tipo de recompensa, "algún tipo de esperanza, no una esperanza proyectada hacia un futuro muy remoto, pero sí algún tipo de esperanza y optimismo... un hábito de secuencias rutinarias, inspiradas por una sensación inquietante de recompensa siempre inminente pero indefinida" (pp. 202-203).

Lo anterior, se encuentra directamente relacionado con el planteamiento de Erickson (2000), acerca de que el primer logro social que debe desarrollar un niño es la confianza básica, lo cual le conferirá en la vida adulta, aun ante situaciones difíciles, la sensación de esperanza, de que las cosas pueden mejorar. El contexto interaccional y situacional tienen una fuerte influencia en esto.

Reitero, como mencioné al principio, que el comportamiento como si tiene un gran espectro que oscila entre lo sano y lo insano, entre un comportamiento conducente a la coherencia y un comportamiento conducente a la incoherencia. Invito al lector a reflexionar sobre sus comportamientos como si, y acerca de cuándo estos fueron coherentes o incoherentes con su forma de pensar y sentir, sanos o insanos tanto para él, como para aquellas personas con las que se relacionó o se relaciona. 


\subsubsection{Integrar o Mistificar}

Integrar: la mentalidad cristiana plantea una dicotomía entre el mal y el bien, entre Dios y el Diablo; es una mirada totalmente polarizada, que promueve un pensamiento que excluye, un pensamiento que ha sido denominado maniqueo ${ }^{7}$ y en el que no caben explicaciones que contemplen el contexto, las circunstancias y lo relacional, lo cual no ayuda a construir una forma incluyente de comprensión.

Este código moral no sólo promueve la perfección, a través de valores como la bondad, la pureza, la castidad, la humildad, la monogamia, como necesarias para alcanzar el reino de los cielos, sino que al mismo tiempo plantea que si se cometen faltas que atenten contra estos valores se pierde la recompensa del cielo: "la salvación". Este código moral permite unos valores, que pueden compartirse y exhibirse, mientras que otros independientemente de las circunstancias son censurados; de esta manera, se abre la puerta al ocultamiento y a la doble moral, a esconder las faltas y comportarse en lo público como si no hubiese falta y se llega incluso a juzgar severamente a quienes se atreven a cuestionar este código moral. Esto se ilustra de manera clara y pormenorizada en la película "El código Da Vinci" Ron Howrd (2006).

Tenemos entonces que las dificultades para integrar los polos que coexisten en nosotros, entre otros obstáculos, tienen que ver con estas cuestiones de orden moral. Para lograr la integridad, requerimos formas de pensamiento que nos permitan considerar que somos buenos y malos al mismo tiempo, que somos falibles. Lo negativo en el maniqueísmo, no es la promoción de los valores enunciados, sino la pretensión de perfección pues como dice Maturana (1993), “...cada vez que uno busca un espacio de convivencia perfecta, se genera una tiranía".

Lo anterior se puede observar en la película rusa "El Estudiante" dirigida por Kirill Serebrennikov (2016) que nos muestra a un estudiante adolescente que al mismo tiempo que lucha por mantener a raya su deseo sexual, se va al extremo, entra en una crisis mística y predica que el mundo se ha rendido al mal y que ya no hay moral. Constantemente sorprende a su madre, a sus compañeros, a profesores y a todo el instituto con sus aseveraciones dogmáticas. Las chicas no deben usar bikini en la clase de natación,

7 El pensamiento maniqueo surgió en la religión y posteriormente se extendió a la política. El Maniqueísmo, surgió de la religión fundada por el príncipe persa Manes (216-277) según la cual existen dos principios reguladores del universo, el Bien y el Mal, que se encuentran en constante lucha y oposición y a los que denomina la Luz y las Tinieblas, respectivamente. Se considera que hace presencia el uno o el otro. El Maniqueísmo político es considerado como la actitud de algunas personas, de dividir las ideas, o personas, en dos grupos irreductibles: los del bando bueno y los del bando malo. El maniqueo en el terreno político asume que él y los que están de acuerdo con él están en el bando de los buenos y los que están en desacuerdo con él están en el bando de los malos. No reconocen nada positivo en el otro bando y lo asumen como el enemigo. No se pueden ver integralmente ni a sí mismos, ni a los otros. 
Sánchez-Rengifo

no se debe enseñar la teoría de la evolución en las clases de ciencias naturales, los chicos y chicas no deben tocarse, etc. De los adultos de su entorno sólo la profesora de biología, la adulta más integrada en ese contexto se interesa seriamente en su caso y decide ayudarlo y confrontarlo. Los otros adultos, su madre, profesores y directivos, que no asumen su propia integración y que no reconocen su propio lado negativo, se comportan temerosos e inseguros ante el adolescente, se muestran incapaces de contenerlo y terminan promoviendo su conducta, creyendo sus mentiras y minimizando su comportamiento patológico, con el resultado de que el muchacho incrimina con mentiras a su profesora de biología de haberlo tocado inadecuadamente y se convierte en asesino de un compañero en "pro del bien". De este tipo de comportamientos hay ejemplos en la historia de la humanidad, tanto en el nivel micro como en el macro.

En consecuencia, en el marco religioso o político, los feligreses o los sujetos al no poder alcanzar la perfección, y ante el miedo que le tienen a su lado oscuro, recurren a ocultar cualquier falta a estos valores, propiciando el que se viva una doble vida: en la vida pública se predica el necesario cumplimiento de estos valores y en la vida privada, puede llegarse, en casos extremos, a practicar todo lo contrario, lo cual hay que ocultar mediante mecanismos conscientes o inconscientes. Si es consciente, se justifica en pro de conseguir el bien y eliminar el mal, y si es inconsciente se lo oculta incluso a sí mismo.

En el contexto de la cultura occidental, se ha informado de escándalos de políticos quienes se presentaban como defensores acérrimos de la moral y que fueron descubiertos, desempeñando en su vida privada las conductas que tanto atacaban en la esfera pública. En la sociedad norteamericana, menciono el caso del demócrata y exgobernador de Nueva York, Eliot Spitzer que se caracterizó en su vida pública por emprender campañas moralizadoras de diferente tipo. En el 2004, siendo fiscal general de New York, hizo arrestar a dieciocho personas, bajo la acusación de formar parte de una red de prostitución. Asumió como gobernador en enero de 2007, y en marzo de 2008 se vio obligado a renunciar a su cargo ante las evidencias que lo acusaban de sostener relaciones con una joven de veintidós años dedicada a la prostitución y a quien al parecer le pagaba sumas exorbitantes con dineros del erario.

También está el caso de Bill Cosby, personaje de la farándula norteamericana al que llamaban "El padre de América", y que después de que varias mujeres lo denunciaran por drogarlas y abusar sexualmente de ellas, pasó a ser denominado "violador".

Es posible comprender que estos personajes, como cualquier hombre o mujer, no sean totalmente coherentes con lo que predican, pero es precisamente la existencia de una moral que no perdona un error, sobre todo a las figuras públicas, lo que contribuye a generar la doble moral, el ocultamiento, y que por ende posibilita la polarización entre la vida privada y la pública. 
Sánchez-Rengifo

La literatura y el cine están llenos de ejemplos de falta de integridad. Veamos algunos:

-En la novela de Lewis (1796), "El Monje": en la que se nos presenta a un monje español llamado Ambrosio, conocido y apreciado en el pueblo como alguien extremadamente cultivado, amoroso y virtuoso, secretamente se deja llevar por la lujuria, llegando al asesinato. Finalmente es condenado a morir a manos de la Inquisición.

-La novela de Patrick Ness (2014), "Un monstruo vino a verme": a través de la elaboración del duelo de un jovencito de trece años cuya madre se está muriendo de cáncer, se muestra la ambivalencia de los seres humanos. Por lo general, la gente no es buena ni mala, sino que en realidad las personas se encuentran entre estas dos fuerzas y a veces se portan bien $\mathrm{y}$ a veces mal, a veces sienten rabia y a veces tristeza, a veces amor y a veces odio. Finalmente, el monstruo le ayuda al joven a enfrentar su verdad, es decir su ambivalencia, su parte oscura y su parte luminosa, a aceptar su dolor, su rabia y también sus sentimientos encontrados alrededor del deseo de que su madre se muriera de una vez por todas y no seguir albergando falsas esperanzas.

- La novela de Stevenson (1991), El extraño caso del Dr. Jekill y Mr. Hyde: en esta novela se representa el ocultamiento de aquellos pensamientos, sentimientos y acciones que al ser censurados socialmente como 'malos', llevan a quienes los experimentan a ocultarlos, mostrando sólo aquella parte que el entorno considera 'buena'. Veamos un fragmento del apéndice de la novela, en el que se observa la escisión del personaje principal:

La casa del Dr. Jekyll tiene dos puertas, una trasera que da a un callejón sombrío y luego a callejuelas que llevan al doctor, en la noche, hasta Soho; la otra, guardada por un honorable mayordomo, pertenece a la fachada, la más noble de una plaza antigua, y recorta la figura alta, distinguida y respetable del doctor, camino de sus reuniones de sociedad o de sus particulares quehaceres caritativos. Las dos puertas llevan cada una a su ámbito: a la sociedad respetable y al placer nocturno. Jekyll viene al gabinete, su laboratorio, desde una u otra, desdoblado en dos personas cada día y cada noche más difíciles de armonizar. Fuera, las calles compartían plazas comunes y en la acera la farola terciaba las luces con sus sombras, tal como Londres acoge, juntos todos los ruidos y sus vientos más dispares, pero el joven doctor no podía concordar sus dos yos irreductibles.

El laboratorio es una habitación tranquila, atestada de instrumentos de química, siempre encendido el fuego de la chimenea, algún libro sobre el brazo del butacón y una mesita cercana con el servicio del té a punto. 
El doctor Jekyll trabajando en este laboratorio, consiguió un día resolver el problema que le atormentaba: sentirse movido por dos tendencias dispares, o, más exactamente no ser uno sino dos, bien y mal, en una naturaleza. Su pócima le permitió pasar del uno al otro yo, ser, por tiempos, una unidad coherente, y ya, en lo sucesivo, según quisiera adoptar esta o aquella personalidad, árbitro de sí. Y aquel día le sacudió la ciencia las almas al doctor hasta saltársele una cercenada y hambrienta, todavía anegada en lodo de abajo y con la vida en carne viva saliéndosele por los sentidos: apareció Hyde. Jekyll y Hyde tuvieron cada uno su puerta, cada uno su vida, cada uno un yo, pero una sola memoria y compartiendo un mismo laboratorio. (p. 200).

Para terminar este aparte invito al lector además de leer esta novela, a ver la película "La cinta blanca" dirigida por Michael Haneke (2009), y a leer la novela de Víctor Hugo (1862) “Los Miserables". En la primera se ve cómo la incoherencia del pastor, quien predica los más altos valores y al mismo tiempo abusa sexualmente de su hija y somete sexual y emocionalmente a su criada, se extiende hasta toda la aldea e involucra en comportamientos dañinos a niños y adultos. En los Miserables, Jean Valjean es el bandido. La novela nos presenta el contexto macro y micro en la historia de este hombre que nos ilustra acerca de cómo un buen miembro de familia llegó a convertirse en un bandido y con quien bastaron dos gestos de bondad sincera: uno de un niño y otro de un monje, para que la parte sana que estaba oculta en este hombre pudiera volver a salir a la luz y recobrara el sentido de esperanza.

Tenemos entonces que, así como no existen en nuestra vida situaciones solamente ubicadas en los extremos del juicio moral 'malo o bueno', tampoco hay personas ubicadas solamente en los extremos. Aunque sí podemos encontrar personas que se inclinan más al extremo de la maldad, con mayor tendencia a la desunión, a la destrucción y al Tánatos, y otras que se aproximan más al extremo de la bondad, que tiende a la unión, a la construcción, al eros. Es necesario tener presente que, en cualquiera de los extremos, el otro siempre está presente, se encuentra en alguna parte $\mathrm{y}$, dependiendo de las circunstancias y de las conexiones humanas que se establezcan, saldrá a la luz o permanecerá oculto.

Entonces, hay que estar atentos a encontrar 'lo bueno de lo malo' y 'lo malo de lo bueno'. Las posiciones radicales y las defensas o ataques a ultranza de cualquier persona o personaje se vuelven entonces sospechosas, porque podemos estar defendiéndonos de lo que nos amenaza internamente y lo atacamos o defendemos en el exterior. Nosotros mismos tenemos la cualidad de sacar lo mejor o lo peor que hay en nosotros mismos y en otros seres humanos.

Es pertinente aclarar, que hay momentos en que es necesario establecer responsabilidades y que hay formas de comportarse que pueden ser valoradas como buenas o malas, que efectivamente tienen consecuencias positivas o negativas tanto en el 
individuo que actúa como en su entorno, y por ende los sujetos deben responsabilizarse y asumir las consecuencias de sus actos.

En este sentido estamos frente a un asunto ético, cada persona adulta es responsable por lo que dice y hace, así como de sus reacciones a lo que dicen y hacen los demás; pues bien sabemos que no hay una sola forma de responder. A un piropo, a una ofensa, las personas reaccionan de manera diferente; si bien hay elementos comunes que obedecen a la predeterminación cultural y que marcarían la tendencia de la respuesta, hay matices individuales y los sujetos pueden dar sorpresas y comportarse de una manera no esperada. La forma como una persona reacciona tiene que ver con la conducta del otro, con el contexto, las relaciones de poder, las historias individuales y con lo que ella es en un momento determinado. Por todo esto, es importante, cuando de adultos se trata, establecer el grado de responsabilidad de los participantes en una interacción.

Con esto quiero aportar claridad en el sentido de que, si queremos ser coherentes, hay que evaluar tanto nuestros comportamientos como los de los otros seres humanos, teniendo en cuenta los diferentes factores intervinientes que nos lleven a comprender las conductas ubicadas en cualquier polaridad, en especial las que tienden a situarse en los extremos. Si se trata de la polaridad bueno y malo afrontamos un asunto ético ${ }^{8}$. Lo que está en cuestión es el comportamiento, no lo que la persona es.

-Mistificar: La mistificación empieza con confusión. A la falta de coherencia en la vida cotidiana, se le ha llamado comportamiento ambiguo o confuso. Podemos encontrar incoherencia entre lo que se dice y lo que se hace, entre el comportamiento público y el privado, y en lo emocional encontramos personas que de pronto se abren y establecen una relación intensa de cercanía y, sorpresivamente, se muestran distantes y se cierran a la relación emocional. A veces cumplen las promesas y a veces no, pero esto no es claro, lo enredan mediante el lenguaje y la relación emocional confusa. Estos comportamientos tienden a provocar confusión en las relaciones interpersonales.

Una persona ambigua, no es confiable, no sabemos a qué atenernos con ella, mientras que la persona que muestra más tendencia a la integridad nos permite ver sus errores y al mismo tiempo que los acepta, se responsabiliza de ellos. Vemos a esta última como una persona que transmite sinceridad, es una persona que cumple sus promesas y por lo tanto es digna de depositar nuestra confianza en ella.

8 Según Ibáñez (citado por Manrique, 1994, p. 57), los seres humanos se organizan alrededor de polaridades básicas que demandan la realización de un juicio. Estas polaridades se plantean en relación a los sujetos, los objetos y los mensajes: "Respecto a los sujetos la polaridad es bueno-malo (juicio ético), respecto a los objetos es bello-feo (juicio estético) y respecto a los mensajes es verdadero-falso (juicio lógico)". 
Un discurso coherente y una persona íntegra se caracterizan porque los componentes de su discurso y su conducta están conectados entre sí de manera lógica, es decir, de manera racional podemos comprender y entender la continuidad, la consistencia existente entre la creencia o forma de pensar, con la forma en que se expresa y finalmente la forma puntual como se actúa. Si hay incongruencias, el sujeto las asume sin intentar ocultarlas actuando como si no existieran. Es importante aclarar que la congruencia sana implica flexibilidad y no un comportamiento rígido y estereotipado. Quien tiene un comportamiento estereotipado, por lo general, tiene miedo a perderse en el movimiento oscilatorio que exige la dinámica de la vida sana.

El concepto de mistificación es el equivalente al de alienación en Marx, aunque en este caso, no se refiere a las relaciones entre las clases sociales, sino a las relaciones intersubjetivas. El término "Mistificación", fue acuñado por Laing (1982) y con él se refiere:

-En las relaciones sociales macro, a una de las formas en que se trata de homogeneizar o igualar a los integrantes de una sociedad. En este sentido el proceso de socialización es en parte mistificación, pues Laing (1978), define la socialización como el proceso mediante el cual la familia y las otras instituciones encargadas de ella, procuran que "cada nuevo recluta de la raza humana se comporte y experimente, sustancialmente, del mismo modo que aquellos que ya están inmersos en la sociedad". Esta homogeneización es una preparación por medio de la cual "se nos enseña lo que hay que experimentar y lo que no hay que experimentar, igual que se nos enseñan los movimientos que hay que hacer y los sonidos que hay que emitir" (Laing, 1978, p. 53).

Esta acepción de la mistificación coincide con el término trivialización, más reciente y acuñado por Von Foerster (1991), para designar la capacidad que tiene la sociedad de programar a sus integrantes y de esta manera restarles impredictibilidad. El producto de este proceso es una persona más o menos mistificada, una persona más o menos alienada, pero a la que "se considera sana, por el hecho de que más o menos actúa como las demás" (Laing, 1978, p. 25). Es decir, entre más obediente sea una persona a las enseñanzas del sistema familiar y social, más mistificada y alienada ${ }^{9}$. Esto tiene una relación directa con el concepto de normalidad que se maneja socialmente, el cual, más que relacionado con la salud de una sociedad o de un individuo, se refiere al concepto estadístico de curva normal, donde el comportamiento que tiende a la cúspide es el mayoritario y se considera normal, simplemente por el hecho de ser mayoritario.

9 Esto nos permite comprender por qué es perfectamente adecuado que los niños lleguen a una etapa en la que no les cuenten todo a sus padres, y que no les obedezcan ciento por ciento. Esta es una buena señal de que se están convirtiendo en personas autónomas. 
-En las relaciones interpersonales, a una de las formas en que los grupos humanos tratan de resolver las contradicciones que tienen lugar en su seno. En este sentido, Laing (1982), explica la mistificación, a partir de dos acepciones, una activa y otra pasiva. En la acepción activa, mistificar es tratar de confundir, ocultar, enmascarar o llevar a una persona a no tener claridad sobre lo que experimenta, lo que está haciendo o lo que está ocurriendo. Un ejemplo lo podemos encontrar en una madre que está llorando y su hijo de seis años se le acerca y le pregunta ¿por qué estas llorando?, la madre le responde en tono quejumbroso y apesadumbrado: yo no estoy llorando, no me pasa nada, estoy bien, estoy cansada. Vemos entonces cómo la madre, no sólo, no le responde adecuadamente al hijo, sino que lo pone a dudar de su propia percepción, por la incongruencia entre lo verbal y lo no verbal, y además le envía el mensaje de que la gente llora cuando está cansada.

En la acepción pasiva, estar mistificado es estar confundido o enredado, aunque necesariamente la persona no se sienta así, o no sea consciente de su estado. En el ejemplo anterior, el niño ocupa la posición pasiva y si las respuestas de su madre reiterativamente son mistificadoras, puede terminar dudando de sus propias percepciones, pues ante la pugna interna entre confiar o no confiar en su madre, él 'prefiere' no desconfiar de ella, pues como le han enseñado que todo lo que su madre hace es por amor a él, le resulta menos doloroso dudar de sus propias percepciones, que del amor de su madre.

La mistificación requiere un tipo especial de relación, donde el que ocupa la posición pasiva no puede oponerse a los atributos que se le imponen, a los intentos de manipulación, ni intentar aclarar las incongruencias de la comunicación. Si este contexto interpersonal existe, es posible mistificar, entre otras, de las siguientes maneras:

- Adjudicando un sentimiento independientemente de lo que la persona siente.

- Adjudicando una responsabilidad independientemente de lo que la persona asume.

- Atribuyendo capacidades o carencias sin referentes empíricos.

- Restándole importancia a los motivos o intenciones de la persona.

- Interpretando las experiencias de la persona sin tener en cuenta su punto de vista.

- Negando la existencia de hechos que la persona dice haber presenciado o escuchado.

En todas las formas de mistificar, una persona está ejerciendo influencia sobre la otra, sobre sus percepciones y experiencias; negando o construyendo sentimientos, pensamientos o acciones que son ajenas y no encajan con la situación real. La mistificación es pues un proceso interpersonal, el sujeto no se puede mistificar a sí mismo.

Es importante aclarar que, aunque una persona trate de ejercer influencia mistificadora sobre otra, si lo hace de manera abierta, así haya presión, persuasión o 
intentos de control, si la otra persona está en una posición que le permita rechazar la influencia, no habrá lugar a mistificación. Es decir, si no se logra confundir al otro y situarlo en una posición insostenible no estamos hablando de mistificación.

Searls (citado por Laing, 1982), propuso conceptos afines al concepto de mistificación, según los cuales se equipara la mistificación con los modos de enloquecer a una persona. Se puede enloquecer a otro, minándole la confianza que tiene sobre sus propias reacciones emocionales y sobre su propia percepción de la realidad. Entre algunos ejemplos podemos citar:

- Someter simultáneamente a una persona a la estimulación y a la frustración.

- Cambiar el estado emocional (serio a divertido) sin cambiar de tema, o viceversa, cambiar de tema sin cambiar el estado emocional.

- Estimular una conducta en una situación en la que sería desastroso que se presente dicha conducta.

- Llamar la atención reiteradamente sobre aspectos de la conducta de una persona, de los que apenas se da cuenta y que discrepan mucho del tipo de persona que cree ser.

La pregunta que surge es: ¿para qué las personas mistifican o entran en relaciones en las que permanecen mistificadas? La respuesta está relacionada con la necesidad que experimentan los sujetos y la familia de mantener una organización que les provea un entorno emocionalmente estable y seguro para desenvolverse, es mejor moverse en lo conocido pues despierta menos temores.

La mistificación funciona para mantener papeles estereotipados, y encajar a las demás personas en un molde prefabricado, a la manera del lecho de Procusto. Los padres luchan por preservar su propia integración, manteniendo sus rígidas preconcepciones acerca de quiénes son y quiénes deben ser, quienes son sus hijos y quiénes deben ser, y la naturaleza de la situación que caracteriza la vida familiar. Son insensibles a las necesidades emocionales de sus hijos, quienes amenazan trastornar sus esquemas preconcebidos, $\mathrm{y}$ enmascaran $\mathrm{u}$ ocultan situaciones perturbadoras en la familia, actuando como si éstas no existiesen. (Laing, 1982, p. 405).

Si alguno de los miembros de una familia reconoce en una situación amenaza o peligro para la estabilidad familiar, es posible que lo oculte y para ello tenga que acudir a enmascarar los hechos, a fin de que no salga la verdad a la luz.

En general, la mistificación es un proceso que emprende un miembro de una pareja o de una familia a fin de no perder la estabilidad, ni las reglas y las pautas que le resultan conocidas. A través de la mistificación se trata de evitar el conflicto y si no se logra, por lo menos se le resta claridad al motivo del mismo y de alguna manera se envían señales de 
que tratar de clarificar el enigma sería algo malo. En consecuencia, el aspecto fundamental de la mistificación es la confusión, que contiene un proceso de falsación que lleva a que, ante una contradicción entre dos personas, una le diga a la otra 'es solo tu imaginación, si ves lo que ves es porque no me quieres' ${ }^{10}$. Por este camino se puede llegar fácilmente a otras formas de mistificación, donde a las personas “...que se salen del estado de alienación predominante son las que la mayoría <<normal>> califica de malas o locas" (Laing, 1978, p. 25).

Una cosa es mistificar y otra engañar. La mistificación es un proceso complejo y refinado donde mistificador y mistificado se encuentran entrampados. En el engaño hay un propósito consciente, de una o varias de las personas en interacción, de engañar y sacar provecho de una situación.

El concepto de mistificación también está en estrecha relación con el de pseudomutualidad, planteado por Wynne et al. (1980). Este concepto enfatiza la necesidad que tienen algunas familias de eliminar las diferencias:

...todas las relaciones interpersonales que persisten están estructuradas en términos de algún tipo de complementariedad o adecuación. Sin embargo, al describir la pseudomutualidad destacamos un esfuerzo de adecuación realizado a expensas de la diferenciación de la identidad de las personas que participan en la relación..., la relación de pseudo-mutualidad implica un dilema característico: la divergencia se percibe como un factor de desquiciamiento de la relación, por lo cual es necesario evitarla pero, si se la evita, la relación no puede crecer. (Wynne et al., 1980, pp. 115-117).

Estos autores aplican el concepto de pseudomutualidad a familias con pacientes esquizofrénicos.

...consiste en la creación de una subcultura familiar generalizada de mitos, leyendas e ideologías que subrayan las consecuencias catastróficas de una divergencia abiertamente reconocida con respecto a la estructura fija de roles familiares. Ya señalamos que incluso una divergencia pequeña puede experimentarse como una amenaza capaz de provocar, por ejemplo, un ataque cardíaco. Las leyendas familiares relacionadas con furia y violencia pueden constituir recordatorios permanentes de las supuestas consecuencias de la divergencia. (Wynne et al., 1980, p. 129).

10 Un ejemplo de esto nos lo proporciona Rosa Montero (2003), cuando narra un episodio de la vida de la escritora George Sand, a quien encontró su marido en una escena romántica con otro hombre, George negando las evidencias le dijo a su marido, " $<<$ Veo perfectamente que ya no me amáis, puesto que creéis en lo que vuestros ojos ven y no en lo que yo os digo>>, le espetó con ofendida dignidad a su marido". 
Sánchez-Rengifo

Esto se encuentra ilustrado en el cuento "La salud de los enfermos" de Cortázar (2002) y en la película “Unas Dulces mentiras" de Julie Bertucelli (2003). También en nuestra realidad lo observamos en aquellas familias donde algunos miembros indican que no se le puede llevar la contraria a otro por el riesgo de que se enferme o muera.

Otro mecanismo que se utiliza es la aprobación indiscriminada de todas las conductas de los miembros de la familia y que estos autores relacionan con el surgimiento de los secretos:

Una consecuencia de la aprobación indiscriminada es el secreto, que trae como resultado esta fórmula: lo que no puede ser aprobado debe permanecer ignorado. Ambos mecanismos impiden que la divergencia ejerza un efecto reconocido y significativo sobre la ideología familiar y la estructura de roles. Se espera que cada miembro de la familia oculte amplias áreas de su experiencia y no establezca comunicación con los otros. A veces las expectativas en cuanto al secreto se expresan en un respeto exagerado por lo que se califica como intimidad, esto es, el derecho invariable de cada miembro de la familia a comentar sólo aquello que desea compartir. (Wynne et al., 1980, pp. 132-133).

Para finalizar, recomiendo dos películas "La fortuna de Qookie" de Robert Altman (1999), que ilustra muy bien 'el comportamiento como sí', en los niveles micro y macro y el proceso de mistificación entre dos hermanas. Y como un ejemplo de integridad la película "Hannah Arendt" de Margareth Von Trotta (2012).

Espero haber logrado que el lector vislumbre la complejidad que implica el ser coherente y por ende las dificultades que afrontamos los seres humanos en el proceso de lograr la coherencia. Y también espero haberle dejado al lector algunas herramientas para evaluarse a sí mismo en cuanto al nivel de coherencia que quiere alcanzar y el punto en el que se encuentra.

Agradecimientos: La escritura de este artículo fue esclarecedora, me permitió atar cabos sueltos en lo intelectual y en lo emocional y darme cuenta de la gran red que me nutre emocional e intelectualmente. Estoy agradecida con colegas y amigas que hicieron una revisión minuciosa del texto; unas desde el comienzo de la escritura, como Myriam Henao quien además de leer detalladamente en varias oportunidades los borradores, hizo comentarios y preguntas que me dieron pistas importantes para mejorar la profundidad y coherencia del artículo. Agradezco también los aportes de Margarita Saldarriaga, Lucía Restrepo, Carolina Blanco, y la lectura minuciosa del borrador final que realizó mi exalumna, Lady Johana Betancourt, pescando detalles y haciendo sugerencias valiosas. A la maestra en Artes plásticas Edna Rocío Pérez, mi reconocimiento a su habilidad y disposición para trabajar en la secuencia gráfica que ilustra el artículo. Muchas gracias a todas de corazón. 


\section{Referencias bibliográficas}

Adichie, C.N. (26 de octubre de 2018). El silencio es un lujo que no podemos permitirnos. El País (España). Recuperado de https:/ / elpais.com/cultura/2018/10/26/babelia/1540567059_956054.html.

Altman, R. (Dir.). (1999). La fortuna de Qookie [cinta cinematográfica]. Estados Unidos: October Films / Moonstone Entertainment.

Anderson, H. (1999). Conversación lenguaje y posibilidades. Bueno Aires, Argentina: Paidós.

Bateson, G. (1976). Pasos hacia una ecología de la mente. Buenos Aires, Argentina: Carlos Lohlé.

Berliner, R. (Dir.). (2016). Nise: el corazón de la locura [cinta cinematográfica]. Brasil: Imagenfilms

Bertucelli, J. (Dir.). (2003). Unas dulces mentiras [cinta cinematográfica]. Francia: Coproducción Francia-Bélgica/ Les Films du Poisson.

Campion, J. (Dir.). (1993). El piano [cinta cinematográfica]. Nueva Zelanda: Jan Chapman Productions CiBy 2000

Central de Radios. (2017). La fábula de Mahatma Gandhi que se viralizó por WhatsApp.

Recuperado de http://www.cdr.cr/2017/02/15/la-fabula-sobre-mahatma-gandhique-se-viralizo-por-whatsapp/.

Cortázar, J. (2002). La salud de los enfermos. Argentina: Ciudad Editorial Sudamericana.

Cyrulnik, B. (2001). La maravilla del dolor. Barcelona, España: Granica S.A.

Eastwood, C. (Dir.). (2008). El sustituto [cinta cinematográfica]. Estados Unidos: Malpaso Productions

Erickson, E. (1981). La adultez. México: Fondo de cultura económica.

Erickson, E. (2000). El ciclo vital completado. Barcelona, España: Paidós.

Foerster, H. (1991). Las semillas de la cibernética. Barcelona, España: Editorial Gedisa.

Ford, D. (2009). El efecto de la sombra [Archivo de video]. Recuperado de https:/ / www.youtube.com/watch?v=9Y-yJliCCsI\&t=332s.

Forman, M. (Dir.). (1975). Atrapado sin salida [cinta cinematográfica]. Estados Unidos: Fantasy Films.

Haneke, M. (2009). La cinta blanca [cinta cinematográfica]. Alemania: Wega Films \& X filme.

History Channel. (2013). El día en que Freud se burló de la Gestapo [Archivo de video]. Recuperado de https://mx.tuhistory.com/noticias/el-dia-que-sigmund-freud-seburlo-de-la-gestapo.

Howrd, R. (Dir.). (2006). El código Da Vinci [cinta cinematográfica]. Estados Unidos: Columbia Pictures.

Hugo, V. (1862). Los miserables. Francia: Planeta

Huneeus, F. (1991). Lenguaje, enfermedad y pensamiento. Chile: Cuatro vientos editorial. 
Sánchez-Rengifo

Laing, R. (1978). La política de la experiencia. La mistificación de la experiencia. Barcelona, España: Grijalbo.

Laing, R. (1982). Mistificación, confusión y conflicto. En I. Boszormemyi y J. Framo (Comp.), Terapia familiar intensiva. Aspectos teóricos y prácticos (pp. 397-418). México: Trillas.

Laing, R., Phillipson, H., y Rusell-Lee, A. (2001). Percepción interpersonal. Argentina: Amorrortu editores.

Lewis, M. (1796). El monje. Inglaterra: Valdemar.

Manrique, R. (1994). La psicoterapia como conversación crítica. Madrid, España: Libertarias.

Maturana, H. (octubre, 1993). El educar y el aprender. En Conferencia "Aprender a Aprender", Colegio san Patricio, Santa Fe de Bogotá, Colombia.

Montero, R. (2003). Historias de mujeres. Madrid, España: Editorial Santillana.

Morin, E. (2001). La mente bien ordenada. España: Seix Barral.

Ness, P. (2011). Un monstruo vino a verme. México: Nube de tinta.

Paz Estéreo. (13 de agosto de 2016). Jaime Garzón "Heriberto de la Calle" entrevista a Horacio Serpa [Archivo de video]. Recuperado de https://www.youtube.com/watch?v=0zbDeUXNSQM.

Ribero, M. (Dir.).(1986). El embajador de la india [cinta cinematográfica]. Colombia: Focine.

Sánchez, L.M. y Escobar, M.C. (2009). Mitos y secretos familiares. Cali, Colombia: Universidad del Valle.

Serebrennikov, K. (2016). El estudiante [cinta cinematográfica]. Rusia: Hype Film.

Stevenson, R. (1991). El extraño caso del Dr. Jekly y Mr. Hyde. Colombia: Editorial Rei Andes Ltda.

Tosky, A. (4 de mayo de 2013). Súper Cantinflas y la relatividad [Archivo de video]. Recuperado de https:// www.youtube.com/watch?v=FOpG9QEOlO0.

Ugazio, V. (2001). Historias permitidas, historias prohibidas. Polaridad semántica familiar y psicopedagógica. España: Paidós.

Von Trotta, M. (Dir.). (2012). Hanna Arendt [cinta cinematográfica]. Alemania: Heimatfilm.

Wasserman, M. (02 de febrero de 2016). El temor a la gente demasiado buena. El Tiempo. Recuperado de https://www.eltiempo.com/archivo/documento/CMS-16576439.

Watzlawick, P., Helmick, J., y Jackson, D.D. (1983). Teoría de la comunicación humana. Barcelona, España: Herder.

Watzlawick, P., y Nardone, G. (2000). Terapia breve, filosofía y arte. Barcelona, España: Herder.

Wynne, L., Bateson, G., Ferreira, A., Rickoff, I., Jackson, D., Weakland, J., y Zuk, G. (1980). Pseudo-mutualidad en las relaciones familiares de los esquizofrénicos. En G. Bateson (Comp.), Interacción familiar (pp. 111-153). Buenos Aires, Argentina: Ediciones de la Bahía. 


\section{OTROS ARTÍCULOS DE PROSPECTIVA No. 30 DE 2020}

\section{EDITORIAL}

Coherencia, integridad y vida cotidiana

Luz Mary Sánchez-Rengifo

\section{ARTÍCULOS}

Trabajo Social y medios de comunicación: perspectivas y posibilidades de encuentro Social

Mercedes Muriel-Saiz

Maribel Martín-Estalayo

Seguridad, afectos y familias. Obstáculos en el proceso de reintegración de personas desmovilizadas de grupos

armados en Santander, Colombia

Jakeline Vargas-Parra

Ángela María Díaz-Pérez

Priscyll Anctil-Avoine

Reflexividad sobre la intervención profesional en duelo con población afectada por el conflicto armado en Colombia

María Cénide Escobar-Serrano

Maritza Charry-Higuera

Natalia Ramírez-Moncada

Ser mujer indígena, náhuatl, casada, migrante, sin trabajo remunerado: una realidad en los albergues jornaleros agrícolas en Colima, México

Nancy Elizabeth Molina-Rodríguez

Tipos y manifestaciones de la violencia de género: una visibilización a partir de relatos de mujeres víctimas en Soacha, Colombia

Diana Carolina Tibaná-Ríos

Diana Alejandra Arciniegas-Ramírez

Ingrid Julieth Delgado-Hernández

Análisis de necesidades en familias monoparentales con jefatura femenina usuarias de servicios sociales de atención primaria en España

Celia María Fernández-Martínez

Manuela Avilés-Hernández

Experiencias de intervención de trabajadoras sociales con trabajadores sexuales masculinos en Bogotá, Colombia Johan Arturo Barrera-Castellanos
Condiciones laborales de trabajadores sociales en hospitales públicos en la provincia de Mendoza,

Argentina

Cecilia Amalia Molina

Yanina Noemi Roslan-Angeloni

Analía Graciela Correa

Viviana Elena Varela

Gubernamentalidad neoliberal: miradas desde las intervenciones del Trabajo Social en el Gran La Plata, Argentina

Paula Mara Danel

Marcela Claudia Velurtas

Agustina María Favero-Avico

Educación superior en Trabajo Social en Chile y formación para la intervención en situación de calle. Desafios desde la evaluación que interventores hacen de sus procesos de práctica pre-profesional

Carlos Alejandro Andrade-Guzmán

Ignacio Andrés Eissmann-Araya

Educación en Derechos Humanos para el Trabajo Social en Chile: una mirada desde los estándares

internacionales

Lury Soledad Reyes-Pérez

Vivianne Soledad Hasse-Riquelme

Luis Marcelo Silva-Burgos

Arriesgar y preservar la vida: derechos humanos, conflicto sociopolítico armado y Trabajo Social en Colombia

Cristian Sebastián Castaño-Orozco

Ricardo Patiño-Martínez

\section{IN MEMORIAM}

Cristina Bautista Taquinás. Mujer indígena Nasa, Trabajadora Social, lideresa del norte del Cauca, Colombia

Alba Nubia Rodríguez-Pizarro

Lady Johanna Betancourt-Maldonado
ARTISTA INVITADO
MALA JUNTA KLAN
Alejandra Gutiérrez-Cárdenas

\section{PROSPECTIVA}

